\section{Surgical outcomes of external dacryocystorhinostomy and risk factors for functional failure: a 10-year experience}

MJ Lee ${ }^{1}$, SI Khwarg ${ }^{2}$, IH Kim ${ }^{3}$, JH Choi ${ }^{4}$, YJ Choi ${ }^{5}$,

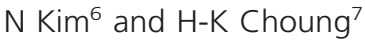

\begin{abstract}
Purpose: To analyze the surgical outcomes of external dacryocystorhinostomy (DCR) and the risk factors associated with functional failure.

Methods: We reviewed the medical records of 769 patients who underwent external DCR for primary lacrimal drainage obstruction between 2005 and 2014. Recorded data included intraoperative anatomical findings, postoperative diagnosis, and surgical outcomes. We performed univariate and multivariate analyses to identify risk factors for functional failure. Results: Of the 769 cases, primary nasolacrimal duct obstruction (NLDO) was diagnosed in 457 cases; common canalicular obstruction in 228 cases; and canalicular obstruction in 84 cases. Anatomical success was achieved in $98.8 \%(760 / 769)$ and functional success in $81.9 \%(630 / 769)$ of the cases. An analysis of 760 anatomically successful DCRs showed that common canalicular obstruction ( $O R=1.752, P=0.014$ ) and canalicular obstruction $(\mathrm{OR}=\mathbf{2 . 0 5 8}$, $P=0.015)$ were independent risk factors for functional failure. In a subgroup analysis of patients with primary NLDO, patients with a small lacrimal sac had a significantly higher risk of functional failure $(\mathrm{OR}=2.500$, $P=0.018$ ).

Conclusions: The overall surgical outcomes of external DCR were favorable in this case series. Site of obstruction was an important risk factor for functional failure in cases with primary lacrimal drainage obstruc tion. A small lacrimal sac was also found to be a risk factor for functional failure in cases with primary NLDO.

Eye (2017) 31, 691-697; doi:10.1038/eye.2016.308; published online 13 January 2017
\end{abstract}

\section{Introduction}

External dacryocystorhinostomy (DCR) is the treatment option for most cases of lacrimal drainage obstruction, including distal canalicular obstruction, common canalicular obstruction, and nasolacrimal duct obstruction (NLDO). Although endonasal DCR has increasingly become more popular over the last decade, many oculoplastic surgeons still prefer external over endonasal DCR, reporting a higher success rate in the former. ${ }^{1}$ Another advantage of external DCR is that it provides a wide and clear surgical field, allowing the lacrimal drainage system and surrounding structures including nasal cavity, ethmoid sinus, and lacrimal sac fossa, to be directly and clearly visualized. Furthermore, the features of lacrimal drainage obstruction can be assessed more precisely intraoperatively during external DCR.

Most studies have reported an excellent success rate of $>90 \%$, when anatomical patency was examined by a lacrimal irrigation test. ${ }^{2}$ Symptomatic success rate is usually reported to be lower than anatomical success rate, lying within the range of $74-83 \% .^{3-5}$ Some patients complain of persistent tearing after DCR even though a lacrimal drainage system is patent and there are no attributable problems in the eyelid or the ocular surface. This discrepancy between anatomical and symptomatic success after DCR is referred to as 'functional failure'.6,7 The ultimate purpose of DCR is the resolution of tearing symptom; therefore, the functional aspect must be emphasized when analyzing surgical outcomes. However, the causes or risk factors for functional failure remain largely undetermined, and an adequate management strategy has yet to be established.
${ }^{1}$ Department of Ophthalmology, Hallym University Sacred Heart Hospital, Anyang, Korea

${ }^{2}$ Department of Ophthalmology, Seoul National University Hospital, Seoul, Korea

${ }^{3}$ SW Bright Eye Clinic, Pocheon, Korea

${ }^{4}$ Department of Ophthalmology, Korean Armed Forces Capital Hospital, Seongnam, Korea

${ }^{5}$ Department of Ophthalmology, Kangdong Sacred Heart Hospital, Hallym University Medical Center, Seoul, Korea

${ }^{6}$ Department of Ophthalmology, Seoul National University Bundang Hospital, Seongnam, Korea

\section{${ }^{7}$ Department of} Ophthalmology, Seoul Metropolitan Government Seoul National University, Boramae Medical Center, Seoul, Korea

Correspondence:

Dr SI Khwarg, Department of Ophthalmology, Seoul National University Hospital, 101 Daehak-ro, Jongno-gu, Seoul 03080, Korea Tel: +82 22072 2879; Fax: +82 27413187 . E-mail: khwarg@snu.ac.kr

Received: 29 March 2016 Accepted: in revised form 27 November 2016; Published online: 13 January 2017 
The aim of this study was to report the surgical outcomes of external DCR in a large case series. A number of clinical and anatomical variables were assessed as potential risk factors for functional failure after external DCR in patients with primary lacrimal drainage obstruction.

\section{Materials and methods}

We reviewed the medical records of all patients who had undergone external DCR performed by one surgeon (SIK) at Seoul National University Hospital over a period of 10 years between 2005 and 2014. Preoperatively, all patients underwent a comprehensive ophthalmologic examination and an assessment of the lacrimal drainage system including the lacrimal syringing test and probing. Dacryocystography or lacrimal scintigraphy was not routinely performed. External DCR operations were recommended for patients who were diagnosed to have NLDO or common canalicular obstruction. This was determined by the presence of a bothersome epiphora symptom and a strong opposite punctal reflux without nasal passage on the lacrimal irrigation test. External DCR operations were also indicated in distal canalicular obstruction. Patients with facial nerve palsy, significant eyelid abnormalities including ectropion and entropion, secondary lacrimal drainage obstruction, or on a followup period of $<4$ months, were excluded from this study. The protocol for this study was approved by the institutional review board of Seoul National University Hospital.

\section{Surgical techniques}

The external DCRs were performed using a standardized procedure described in our previous reports. ${ }^{8-10}$ Bone was removed from beneath the medial canthal tendon superiorly, superomedial part of the nasolacrimal duct inferiorly, posterior lacrimal crest posteriorly, and frontal process of the maxilla anteriorly. All ethmoidal air cells between the lacrimal sac and the nasal mucosa were carefully removed. The vertical size of osteotomy was measured intraoperatively. Nasal mucosal and lacrimal mucosal flaps were made, and both, the posterior and anterior flaps were sutured. In most instances, a silicone bicanalicular tube (solid tube, $0.064 \mathrm{~cm}$ diameter, C-Line canaliculus intubation set 8590450; Medtronic Ophthalmics, Jacksonville, FL, USA) was inserted. When stenosis or obstruction was present at the common canaliculus or distal canaliculus, double silicone intubation was performed after internal excision of the obstructed portion of the canaliculus. ${ }^{10}$

After surgery, the intraoperative anatomical findings were recorded in a prescribed form. ${ }^{8}$ These findings included the width of the nasal cavity; thickness of the lacrimal bone (thin, moderate, and thick); thickness of the maxilla (thin, moderate, thick); severity of the ethmoid sinus intervention between the lacrimal sac fossa and nasal cavity (mild, moderate, severe); vertical size of the lacrimal sac (small, moderate, and large); and the presence of mucous dacryocystitis. The width of the nasal cavity was evaluated by measuring the distance from the nasal septum to the lateral nasal wall after nasal mucosal shrinkage using variably sized Frazier suction tips. A narrow cavity was defined as one through which a 3-mm diameter suction tip could not pass or could barely pass, a moderate cavity as one through which a 5-mmdiameter suction tip could easily pass, and a wide cavity as one through which a 7-mm diameter suction tip could pass. The severity of the ethmoid sinus intervention was determined by evaluating the ethmoid sinus space after removal of the anterior lacrimal crest, bony lacrimal sac fossa, and ethmoidal air cells. We defined mild ethmoid sinus intervention as air cells occupying the superior half between the lacrimal sac and nasal mucosa, and moderate as air cells occupying the superior two thirds of the medial space of the lacrimal sac fossa. Severe ethmoid sinus intervention was defined as air cells completely occupying the lacrimal sac fossa. The size of the lacrimal sac was evaluated on the vertical height of the cavity created by making a vertical incision on the medial wall of the lacrimal sac as follows: small $(<5 \mathrm{~mm})$, moderate $(5-10 \mathrm{~mm})$, and large $(>10 \mathrm{~mm})$. The postoperative diagnosis was determined based on the intraoperatively confirmed site of obstruction (NLD, common canaliculus, and distal canaliculus).

Postoperatively, all patients received antibiotic steroid eyedrops (Forus, neomycin sulfate $3.5 \mathrm{mg} / \mathrm{ml}$; dexamethasone $1 \mathrm{mg} / \mathrm{ml}$, polymyxin B sulfate 6000 $\mathrm{IU} / \mathrm{ml}$, Sam Il Pharm, Seoul, Korea) four times per day for 4 weeks, and 2-3 times per day thereafter.

\section{Outcome assessment}

All patients were followed-up after 1 week, 1 month, and between 4 and 6 months postoperatively, and then variably thereafter. The silicone tube was removed 4-6 months after surgery. At each visit, tearing was checked and a lacrimal syringing test was performed. The surgical outcome was assessed anatomically and functionally based on records from the last visit. Anatomical success was defined as patent irrigation without significant reflux on a syringing test. Functional success was defined as absence of tearing assessed using Munk's score. ${ }^{11}$ Epiphora of grade 0 or 1 (no epiphora or occasional epiphora requiring dabbing less than twice a day) was considered as success, whereas epiphora from 
grade two or more (epiphora requiring dabbing twice and over) was defined as failure.

\section{Statistical analysis}

The $\chi^{2}$-test or Student's $t$-test was used to determine whether there were significant differences between surgical success and failure groups by demographic and anatomical factors. Logistical regression was used to estimate the associations between variables and the surgical outcomes. The univariate analysis included all factors that could have potentially affected the outcomes. Factors found to be associated with the outcome at a significance level of $P<0.1$ using univariate analysis were included in the multivariate analysis. Data were entered in a Microsoft Excel spread sheet (Microsoft, Redmond, WA, US) and exported to the IBM SPSS Statistics program version 21.0 (IBM, Armonk, NY, USA).

\section{Results}

\section{Patient characteristics}

A total of 872 external DCRs were performed during the study period. Of these, 52 cases had a short postoperative follow-up period, 39 cases had lacrimal drainage obstruction from secondary causes, 4 cases had facial nerve palsy, and 8 cases had significant lid abnormalities. These cases were excluded from the analysis. As a result, 769 cases from 603 patients were included in this study. The mean age was $57.7 \pm 12.2$ years (range $3-84$ ), and most patients $(77.6 \%, 468$ of 603$)$ were women. The mean duration of tearing was $62.8 \pm 92.3$ months (range 1-720). Of the 769 DCRs, postoperative diagnoses included 457 cases of primary NLDO with patent canaliculi; 228 cases of common canalicular obstruction; and 84 cases of canalicular obstruction. The mean postoperative followup period was $11.0 \pm 16.3$ months (range 4-108). Anatomical success was achieved in 760 (98.8\%) cases, and functional success in $630(81.9 \%)$ cases.

\section{Risk factors for functional failure after external DCR in primary lacrimal drainage obstruction}

We sought to analyze factors associated with surgical outcomes for external DCR in patients with primary lacrimal drainage obstruction. However, this was difficult to ascertain as the anatomical success rate was $98.8 \%$ (760/769) with only 9 patients who showed anatomical failure. Therefore, we compared the demographic factors and intraoperative anatomical findings between the functional success group $(n=630)$ and the functional failure group $(n=130)$ in anatomically successful DCRs (Table 1). Functionally failed DCR cases showed a shorter tearing duration than functionally successful DCR cases $(P=0.045, t$-test $)$. Among intraoperative anatomical findings, site of obstruction, size of lacrimal sac, and the presence of mucous dacryocystitis were statistically different between two groups $(P=0.000, P=0.023$ and $P=0.001$ respectively, $\chi^{2}$-test, Table 1 ). Table 2 shows the results of the univariate and multivariate logistic regression analysis. Univariate analysis identified common canalicular or canalicular obstruction, presence of a small lacrimal sac, and absence of mucous dacryocystitis as possible risk factors for functional failure after external DCR. In multivariate logistic analysis, the site of obstruction and absence of mucous dacryocystitis were identified as independent risk factors for functional failure after external DCR. Common canalicular obstruction increased the risk of functional failure by 1.75 $(P=0.014)$, while canalicular obstruction doubled the risk $(P=0.015)$. Absence of mucous dacryocystitis was also associated with functional failure based on multivariate analysis, but this only achieved borderline significance $(P=0.047)$.

\section{Risk factors for functional failure after external DCR in primary NLD}

We performed subgroup analysis that focused on the primary NLDO $(n=453)$ group, excluding patients with common canalicular obstruction and canalicular obstruction. We compared demographic factors and intraoperative anatomical findings between the functional success group $(n=396)$ and the functional failure group $(n=57)$. The distribution of lacrimal sac size was significantly different between the two groups $(P=0.040$, Table 3). Univariate logistic regression analysis, and subsequent multivariate logistic regression analysis revealed that the presence of a small lacrimal sac was the only independent risk factor for functional failure in primary NLDO (Table 4).

\section{Discussion}

In this study, the anatomical success rate of external DCR was $98.8 \%(760 / 769)$ in patients with primary lacrimal outflow obstruction, higher than that reported in previous studies ( 90\%). ${ }^{12,13}$ However, direct comparison between studies is limited because of the differences in techniques, follow-up period, and definition of success in these studies. In most studies, however, functional success was assessed based on improvement in tearing symptom or patient's satisfaction. In this study, the functional success rate was $81.9 \%(630 / 769)$, which is comparable with that in previous studies which have reported success rate ranging from 71 to $92 \% .^{3-5,14}$ 
Table 1 Demographic and intraoperative anatomical findings of 760 anatomically successful DCRs for primary lacrimal drainage obstruction; comparison between functional success and failure groups

\begin{tabular}{|c|c|c|c|}
\hline & Functional success $(\mathrm{n}=630)$ & Functional failure $(\mathrm{n}=130)$ & P-value ${ }^{\mathrm{a}}$ \\
\hline \multicolumn{4}{|l|}{ Demographic factors } \\
\hline Age (mean $\pm S D$; years) & $57.5 \pm 12.7$ & $58.3 \pm 10.1$ & 0.469 \\
\hline Gender (F:M) & 492:138 & 101:29 & 0.908 \\
\hline Laterality (Rt:Lt) & 292:338 & $71: 59$ & 0.101 \\
\hline Duration of symptom (mean $\pm \mathrm{SD}$; months) & $65.32 \pm 97.42$ & $51.86 \pm 62.13$ & 0.045 \\
\hline \multicolumn{4}{|l|}{ Intraoperative findings } \\
\hline \multirow[t]{3}{*}{ Width of the nasal cavity, no (\%) } & Open 191 (30.3) & Open 38 (29.2) & \multirow[t]{3}{*}{0.970} \\
\hline & Moderate 238 (37.8) & Moderate 50 (38.5) & \\
\hline & Narrow 201 (31.9) & Narrow 42 (32.3) & \\
\hline \multirow[t]{3}{*}{ Lacrimal bone thickness, no (\%) } & Thin 438 (69.5) & Thin $100(76.9)$ & \multirow[t]{3}{*}{0.149} \\
\hline & Moderate 108 (17.1) & Moderate 20 (15.4) & \\
\hline & Thick 84 (13.3) & Thick $10(7.7)$ & \\
\hline \multirow[t]{3}{*}{ Maxilla bone thickness, no (\%) } & Thin $57(9.0)$ & Thin 11 (8.5) & \multirow[t]{3}{*}{0.873} \\
\hline & Moderate 310 (49.2) & Moderate 61 (46.9) & \\
\hline & Thick 263 (41.7) & Thick 58 (44.6) & \\
\hline \multirow[t]{4}{*}{ Ethmoid sinus anteriorization, no (\%) } & Absent 58 (9.2) & Absent $8(6.2)$ & \multirow[t]{4}{*}{0.584} \\
\hline & Mild 149 (23.7) & Mild 31 (23.8) & \\
\hline & Moderate $182(28.9)$ & Moderate 35 (26.9) & \\
\hline & Severe 241 (38.3) & Severe $56(43.1)$ & \\
\hline \multirow{3}{*}{ Site of obstruction, no (\%) } & NLDO 396 (62.9) & NLDO 57 (43.8) & \multirow[t]{3}{*}{0.000} \\
\hline & CCO $173(27.5)$ & CCO $52(40.0)$ & \\
\hline & CO $61(9.7)$ & CO $21(16.2)$ & \\
\hline \multirow[t]{3}{*}{ Size of the lacrimal sac, no (\%) } & Small $106(16.8)$ & Small 31 (23.8) & \multirow[t]{3}{*}{0.023} \\
\hline & Moderate 207 (32.9) & Moderate 50 (38.5) & \\
\hline & Large 317 (50.3) & Large 49 (37.7) & \\
\hline Presence of mucous dacryocystitis, no (\%) & $207(32.9)$ & $24(18.5)$ & 0.001 \\
\hline
\end{tabular}

Abbreviations: CCO, common canalicular obstruction; CO, canalicular obstruction; F, female; Lt, left; M, male; NLDO, nasolacrimal duct obstruction;

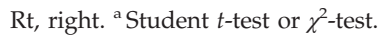

Table 2 Univariate and multivariate analyses for risk factors associated with functional failure of anatomically successful external DCR in patients with primary lacrimal drainage obstruction

\begin{tabular}{lcc}
\hline & Odds ratio (95\% CI) & P-value \\
\hline Univariate & & 0.135 \\
$\quad$ Duration of symptom & $0.998(0.995-1.001)$ & 0.000 \\
$\quad$ Site of obstruction (reference, nasolacrimal duct) & $2.088(1.377-3.166)$ & 0.001 \\
$\quad$ Common canaliculus & $2.392(1.355-4.222)$ & 0.003 \\
$\quad$ Canaliculus & & 0.025 \\
$\quad$ Size of the lacrimal sac (reference, large lacrimal sac) & $1.892(1.147-3.121)$ & 0.013 \\
$\quad$ Small lacrimal sac & $1.563(1.015-2.405)$ & 0.042 \\
$\quad$ Moderate lacrimal sac & $2.161(1.347-3.469)$ & 0.001 \\
Absence of mucous dacryocystitis & $\mathrm{NA}$ & 0.128 \\
Multivariate & & 0.013 \\
$\quad$ Duration of symptom & $1.752(1.123-2.733)$ & 0.014 \\
Site of obstruction (reference, nasolacrimal duct) & $2.058(1.152-3.706)$ & 0.015 \\
$\quad$ Common canaliculus & $\mathrm{NA}$ & 0.320 \\
$\quad$ Canaliculus & $\mathrm{NA}$ & 0.389 \\
$\quad$ Size of the lacrimal sac (reference large lacrimal sac) & 0.439 \\
$\quad$ Small lacrimal sac & $1.674(1.006-2.786)$ & 0.047 \\
$\quad$ Moderate lacrimal sac & & \\
Absence of mucous dacryocystitis & & \\
\hline
\end{tabular}

Abbreviations: CI, confidence interval; NA, not available because criteria of inclusion in multivariate model not met. 
Few studies have investigated the factors associated with DCR outcomes. Most studies analyzed basic clinical parameters, unintentionally collected anatomical parameters, or postoperative endoscopic findings. ${ }^{15,16}$ However, several anatomical structures constituting DCR fields could theoretically affect surgical outcomes.
We postulated that a narrow nasal cavity, a thick maxilla, severe anteriorization of the ethmoid sinus, canalicular stenosis or obstruction, a small lacrimal sac, and absence of mucous dacryocystitis could be possible risk factors for surgical failure of external DCR. These factors were systematically recorded and analyzed along with other

Table 3 Demographic and intraoperative anatomical findings of 453 anatomically successful DCRs for primary nasolacrimal duct obstruction excluding canalicular or common canalicular obstruction; comparison between functional success and failure groups

\begin{tabular}{|c|c|c|c|}
\hline & Functional success $(\mathrm{n}=396)$ & Functional failure $(\mathrm{n}=57)$ & P-value ${ }^{\mathrm{a}}$ \\
\hline \multicolumn{4}{|l|}{ Demographic factors } \\
\hline Age (mean $\pm S D ;$ years $)$ & $56.4 \pm 13.3$ & $56.5 \pm 9.6$ & 0.960 \\
\hline Gender (F:M) & $310: 86$ & $50: 7$ & 0.066 \\
\hline Laterality (Rt:Lt) & $171: 225$ & $32: 25$ & 0.087 \\
\hline Duration of symptom (mean $\pm S D$; months) & $66.3 \pm 109.3$ & $46.2 \pm 48.7$ & 0.172 \\
\hline \multicolumn{4}{|l|}{ Intraoperative findings } \\
\hline Membrane at the internal punctum, no (\%) & $18(4.5)$ & $6(10.5)$ & 0.059 \\
\hline \multirow[t]{3}{*}{ Width of the nasal cavity, no (\%) } & Open $121(30.6)$ & Open $20(35.1)$ & \multirow[t]{3}{*}{0.786} \\
\hline & Moderate 147 (37.1) & Moderate 20 (35.1) & \\
\hline & Narrow 128 (32.3) & Narrow 17 (29.8) & \\
\hline \multirow[t]{3}{*}{ Lacrimal bone thickness, no (\%) } & Thin $273(68.9)$ & Thin $44(77.2)$ & \multirow[t]{3}{*}{0.208} \\
\hline & Moderate 70 (17.7) & Moderate 10 (17.5) & \\
\hline & Thick 53 (13.4) & Thick 3 (5.3) & \\
\hline \multirow[t]{3}{*}{ Maxilla bone thickness, no (\%) } & Thin 43 (10.9) & Thin 3 (5.3) & \multirow[t]{3}{*}{0.274} \\
\hline & Moderate 179 (45.2) & Moderate 31 (54.4) & \\
\hline & Thick 174 (43.9) & Thick 23 (40.4) & \\
\hline \multirow[t]{4}{*}{ Ethmoid sinus anteriorization, no (\%) } & Absent 38 (9.6) & Absent 6 (10.5) & \multirow[t]{4}{*}{0.637} \\
\hline & Mild 98 (24.7) & Mild 10 (17.5) & \\
\hline & Moderate $106(26.8)$ & Moderate 15 (26.3) & \\
\hline & Severe $154(38.9)$ & Severe $26(45.6)$ & \\
\hline \multirow[t]{3}{*}{ Size of the lacrimal sac, no (\%) } & Small 46 (11.6) & Small $12(21.1)$ & \multirow[t]{3}{*}{0.040} \\
\hline & Moderate $120(30.3)$ & Moderate 21 (36.8) & \\
\hline & Large 230(58.1) & Large $24(42.1)$ & \\
\hline Presence of mucous dacryocystitis, no (\%) & $183(46.2)$ & $21(36.8)$ & 0.184 \\
\hline
\end{tabular}

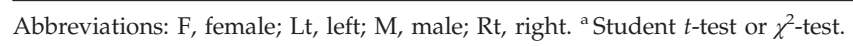

Table 4 Univariate and multivariate analyses for risk factors associated with functional failure of anatomically successful external DCR in patients with primary nasolacrimal duct obstruction

\begin{tabular}{lcr}
\hline & Odds ratio (95\% CI) & P-value \\
\hline Univariate & & 0.105 \\
Female & $1.982(0.867-4.527)$ & 0.068 \\
Right side & $1.684(0.962-2.948)$ & 0.067 \\
Membrane at the internal punctum & $2.471(0.937-6.511)$ & 0.045 \\
Size of the lacrimal sac (reference, large lacrimal sac) & & 0.018 \\
$\quad$ Small lacrimal sac & $2.500(1.167-5.356)$ & 0.105 \\
$\quad$ Moderate lacrimal sac & $1.677(0.897-3.136)$ & 0.187 \\
Multivariate & NA & 0.084 \\
Female & NA & 0.089 \\
Right side & & 0.045 \\
Membrane at the internal punctum & 0.018 \\
Size of the lacrimal sac (reference, large lacrimal sac) & 0.105 \\
$\quad$ Small lacrimal sac & $1.600(1.167-5.356)$ & $(0.897-3.136)$ \\
$\quad$ Moderate lacrimal sac & & \\
\hline
\end{tabular}

Abbreviations: CI, confidence interval; NA, not available because criteria of inclusion in multivariate model not met. 
clinical factors. Among these factors, the site of the obstruction was the most significant risk factor for functional failure after external DCR. In this study, common canalicular obstruction or canalicular obstruction were independently associated with functional failure with a large number of patients. These results are in agreement with data from earlier, smaller studies. ${ }^{17,18}$ Choi et al ${ }^{18}$ evaluated the outcome of endoscopic DCR based on the obstruction level using dacryocystography and reported that obstruction at the lacrimal sac showed the most unsuccessful results, followed by common canalicuar obstruction. In our opinion, the common canaliculus or distal canaliculus area is the narrowest portion through the lacrimal drainage system when the lacrimal sac is anastomosed with the nasal space bypassing the NLD that might act as a bottleneck in the tear drainage pathway even when it is anatomically patent. Rose has also previously described the lacrimal canaliculus as a conduit with a relatively high hydraulic resistance and has suggested that persistent flow symptoms can be caused by inadequate canalicular conductance after anatomically successful DCRs. ${ }^{19}$

In this study, we also analyzed risk factors for functional failure in the primary NLDO subgroup and found that a small lacrimal sac was the only independent risk factor. There have been a few reports showing that lacrimal sac size could be a predicting factor for the anatomical success of endonasal DCR. ${ }^{20,21}$ Mannor and Milliman ${ }^{20}$ estimated the lacrimal sac size preoperatively using dacryocystography and reported that patients with a large sac showed a significantly higher success rate than those with a small lacrimal sac (82 vs 29\%). This is in agreement with the results of another study, which showed that an intraoperatively observed small lacrimal sac was associated with failure of endonasal DCR. ${ }^{21}$ The causal relationship between lacrimal sac size and the functional failure of DCR has been unclear up until now. We speculate that the cicatrized and contracted lacrimal sac impinges upon the transmission of hydrostatic pressure resulting in a decrease in lacrimal pump activity. In this regard, silicone tube insertion might be helpful in facilitating the tear flow through capillary action. However, further studies will be needed to prove this theory.

We observed thin membranous structures at the internal punctum of the lacrimal sac in $5.5 \%$ of patients with primary NLDO. There has been a debate about the anatomical existence of a valve structure around the internal punctum even in recent cadaveric studies. Zoumalan et $a l^{22}$ demonstrated that there were variable valve-like structures at the canalicular/lacrimal sac junction in $59.7 \%$ (74 of 124 lacrimal systems) of cadavers. Whereas, Orhan et $a l^{23}$ dissected 20 specimens and reported that they had not observed the valve structure macroscopically. However, they noted that swelling was present around the opening hole of the common canaliculus in some cases. These anatomical studies were conducted on subjects with normal lacrimal systems, while we examined the internal punctal area in patients with nasolacrimal duct obstruction. Therefore, the results may not be directly comparable. In our opinion, the thin membranous structure may be either a prominent normal mucosal fold at the internal punctum or fibrinous condensation due to chronic inflammation. One previous study emphasized the need for a careful inspection of the internal canalicular aperture and proper membranectomy to enhance surgical outcomes for external DCR. ${ }^{24}$ As such, we carefully remove the membrane and inserted double silicone tubes. Our success rate appeared to be unaffected by the presence of the membrane (Tables 3 and 4).

The strengths of this study are the uniformity in the surgical procedures as it was performed by a single surgeon, the standardized description of intraoperative findings, and the large number of cases that enabled the use of multivariate analysis. However, there are some limitations to this study. First, we only included patients who were followed up for more than 4 months, and some were included even though they were not followed up after tube removal. Olver ${ }^{25}$ suggested that the outcome of DCR should be assessed over a minimum of 6 months after surgery and for at least 3 months after tube removal. Second, we did not use the fluorescein dye disappearance test, only the lacrimal syringing test to evaluate anatomical success rate, which might explain the high anatomical success rate reported in this study. Finally, the assessment of intraoperative findings are subjective; however, we tried to ensure standardization by having the same surgeon perform all the assessment.

In conclusion, the success rate of external DCR was $98.8 \%$ anatomically and $81.9 \%$ functionally in a large case series with primary lacrimal drainage obstruction. The strongest risk factor for functional failure was the site of obstruction; common canalicular obstruction and canalicular obstruction significantly increased the risk. In cases with primary NLDO, a small lacrimal sac was associated with functional failure. The lacrimal sac is a key structure influencing the surgical outcome. Therefore, careful inspection of the lacrimal sac during the DCR procedure should be emphasized to lacrimal surgeons. Descriptions of the vertical size, mucosal swelling and fibrosis, and the appearance of the internal punctal area are helpful in predicting functional success following external DCR. 


\section{Summary}

What was known before

- Numerous studies have shown that the outcomes of external dacryocystorhinostomy were excellent anatomically and functionally. However, functional success rate is known to be somewhat lower than anatomical success rate, and the risk factors for functional failure were still ambiguous.

\section{What this study adds}

- This study reported the success rate of external DCR was $98.8 \%$ anatomically and $81.9 \%$ functionally in a large case series with primary lacrimal drainage obstruction. Multivariate analyses revealed that common canalicular obstruction and canalicular obstruction significantly increased the risk for functional failure after external dacryocystorhinostomy for primary lacrimal drainage obstruction. In subgroup analysis targeting nasolacrimal duct obstruction, small size lacrimal sac was the significant risk factor for functional failure.

\section{Conflict of interest}

The authors declare no conflict of interest.

\section{References}

1 Barmettler A, Ehrlich JR, Lelli G Jr. Current preferences and reported success rates in dacryocystorhinostomy amongst ASOPRS members. Orbit 2013; 32(1): 20-26.

2 Huang J, Malek J, Chin D, Snidvongs K, Wilcsek G, Tumuluri $\mathrm{K}$ et al. Systematic review and meta-analysis on outcomes for endoscopic versus external dacryocystorhinostomy. Orbit 2014; 33(2): 81-90.

3 Kashkouli MB, Mirzajani H, Jamshidian-Tehrani M, Shahrzad S, Sanjari MS. Fluorescein dye disappearance test: a reliable test in assessment of success after dacryocystorhinostomy procedure. Ophthal Plast Reconstr Surg 2015; 31(4): 296-299.

4 Fayers T, Laverde T, Tay E, Olver JM. Lacrimal surgery success after external dacryocystorhinostomy: functional and anatomical results using strict outcome criteria. Ophthal Plast Reconstr Surg 2009; 25(6): 472-475.

5 Delaney YM, Khooshabeh R. Fluorescein transit test time and symptomatic outcomes after external dacryocystorhinostomy. Ophthal Plast Reconstr Surg 2002; 18(4): 281-284.

6 Shams PN, Chen PG, Wormald PJ, Sloan B, Wilcsek G, $\mathrm{McNab} \mathrm{A}$ et al. Management of functional epiphora in patients with an anatomically patent dacryocystorhinostomy. JAMA Ophthalmol 2014; 132(9): 1127-1132.

7 Sahlin S, Rose GE. Lacrimal drainage capacity and symptomatic improvement after dacryocystorhinostomy in adults presenting with patent lacrimal drainage systems. Orbit 2001; 20(3): 173-179.

8 Lee MJ, Khwarg SI, Choung HK, Kim N. Associated factors of functional failure of external dacryocystorhinostomy. Can J Ophthalmol 2014; 49: 40-44.
9 Choung HK, Khwarg SI. Selective non-intubation of a silicone tube in external dacryocystorhinostomy. Acta Ophthalmol Scand 2007; 85(3): 329-332.

10 Hwang SW, Khwarg SI, Kim JH, Choung HK, Kim NJ. Bicanalicular double silicone intubation in external dacryocystorhinostomy and canaliculoplasty for distal canalicular obstruction. Acta Ophthalmol 2009; 87(4): 438-442.

11 Munk PL, Lin DT, Morris DC. Epiphora: treatment by means of dacryocystoplasty with balloon dilation of the nasolacrimal drainage apparatus. Radiology 1990; 177(3): 687-690.

12 Erdol H, Akyol N, Imamoglu HI, Sozen E. Long-term followup of external dacryocystorhinostomy and the factors affecting its success. Orbit 2005; 24(2): 99-102.

13 Saiju R, Morse LJ, Weinberg D, Shrestha MK, Ruit S. Prospective randomised comparison of external dacryocystorhinostomy with and without silicone intubation. Br J Ophthalmol 2009; 93(9): 1220-1222.

14 Moore WM, Bentley CR, Olver JM. Functional and anatomic results after two types of endoscopic endonasal dacryocystorhinostomy: surgical and holmium laser. Ophthalmology 2002; 109(8): 1575-1582.

15 Mak ST, Io IY, Wong AC. Prognostic factors for outcome of endoscopic dacryocystorhinostomy in patients with primary acquired nasolacrimal duct obstruction. Graefes Arch Clin Exp Ophthalmol 2013; 251(5): 1361-1367.

16 Eyigor H, Unsal AI, Unsal A. The role of accompanying sinonasal abnormalities in the outcome of endonasal dacryocystorhinostomy. Am J Rhinol 2006; 20(6): 620-624.

17 Konuk O, Kurtulmusoglu M, Knatova Z, Unal M. Unsuccessful lacrimal surgery: causative factors and results of surgical management in a tertiary referral center. Ophthalmologica 2010; 224(6): 361-366.

18 Choi JC, Jin HR, Moon YE, Kim MS, Oh JK, Kim HA et al. The surgical outcome of endoscopic dacryocystorhinostomy according to the obstruction levels of lacrimal drainage system. Clin Exp Otorhinolaryngol 2009; 2(3): 141-144.

19 Rose GE. The lacrimal paradox: toward a greater understanding of success in lacrimal surgery. Ophthal Plast Reconstr Surg 2004; 20(4): 262-265.

20 Mannor GE, Millman AL. The prognostic value of preoperative dacryocystography in endoscopic intranasal dacryocystorhinostomy. Am J Ophthalmol 1992; 113(2): 134-137.

21 Hammoudi DS, Tucker NA. Factors associated with outcome of endonasal dacryocystorhinostomy. Ophthal Plast Reconstr Surg 2011; 27(4): 266-269.

22 Zoumalan CI, Joseph JM, Lelli Jr GJ, Segal KL, Adeleye A, Kazim M et al. Evaluation of the canalicular entrance into the lacrimal sac: an anatomical study. Ophthal Plast Reconstr Surg 2011; 27(4): 298-303.

23 Orhan M, Govsa F, Saylam C. Anatomical details used in the surgical reconstruction of the lacrimal canaliculus: cadaveric study. Surg Radiol Anat 2009; 31(10): 745-753.

24 Boboridis KG, Bunce C, Rose GE. Outcome of external dacryocystorhinostomy combined with membranectomy of a distal canalicular obstruction. Am J Ophthalmol 2005; 139(6): 1051-1055.

25 Olver JM. The success rates for endonasal dacryocystorhinostomy. Br J Ophthalmol 2003; 87(11): 1431. 